\title{
Research on the Alleys System and Commercial Activities during the Qianlong Dynasty in Qianmen Area, Beijing
}

\author{
Sisi XIA ${ }^{1}$ \\ ${ }^{1}$ School of Architecture, Southeast University, No. 2, Sipailou, Xuanwu District, Nanjing 210096, Jiangsu Province, China \\ seu_xiasisi@outlook.com
}

Key words: Qianmen Area, Qianlong Dynasty, Alleys System, Commercial Activities

\begin{abstract}
:
Based on the basic judgment that commercial buildings have a high demand for traffic accessibility, this study analyses the integration degree and selectivity of the streets and alleys in the spatial syntax. It superimposes the different drawing forms of the buildings along the streets in the whole map of the Qianlong capital. Determine the public attributes that may correspond to the four architectural forms along the street during the Qianlong Dynasty in the Qianmen area of Beijing, and then analyse the trend of commercial activities in this area. According to the degree of agglomeration of commerce along the street, the commercial front street and back street of the area are distinguished, providing a research basis for the development context and path of commercial activities in the area.
\end{abstract}

\section{INTRODUCTION}

As the capital of our country, Beijing has a long history of more than three thousand years. The Qianmen area is located outside Zheng Yang Men, Beijing. The boundary of this study north to Qianmen Street, south to Zhushikou Street, east to Chongwenmen Street and west to Xuanwumen Street. (Figure 1) This area is the most representative folk and traditional business district in Beijing, and also an important cultural highlight ("Beijing History" Writing Group, 1985). In the Liao Dynasty, the Qianmen area was located in the eastern suburbs of the city from Guang'anmen Street (Wu Changyuan, Qing Dynasty). After the Jin and Yuan Dynasties, many oblique streets are spontaneously formed from Shi Ren Men to Zheng Yang Men, connecting the new capital and the old capital (Xiong Mengxiang, Yuan Dynasty). The commerce in the Qianmen area originated in the Yuan Dynasty and matured in the Ming Dynasty. In the mid-Ming Dynasty, this place had become an important commercial area in Beijing (Ming Hui Yao, Ming Dynasty; Chen Wei. 2007) . In the Qing Dynasty, with the influence of various factors, this area gradually developed into the most prosperous commercial cluster among Beijing. A wide variety of businesses were gathered in Qianmen area, such as retail business, theater,

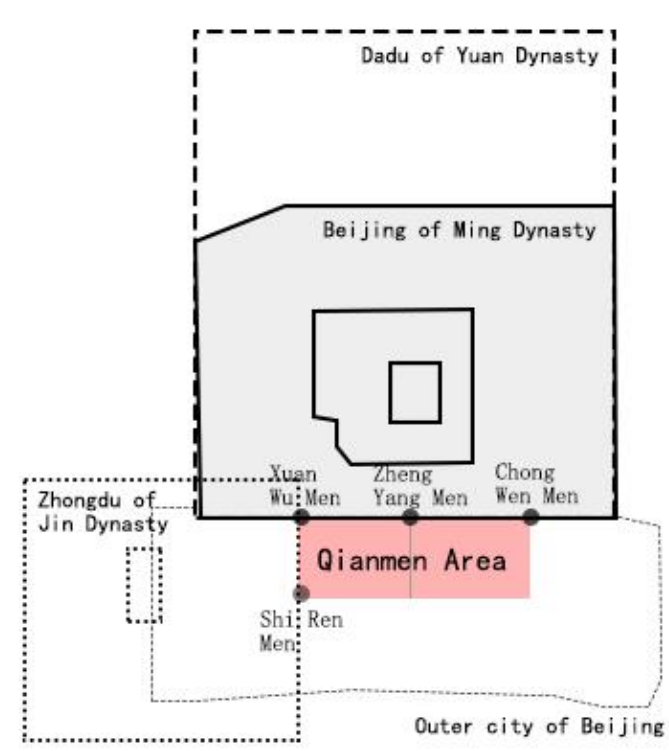

Figure 1. Location of Qianmen area in Ming Dynasty

guild hall, restaurant catering, hotel accommodation (Shun Tian Fu Zhi, Qing Dynasty; Da Qing Hui Dian Ze Li, Qing Dynasty) . With the help of a dense and convenient street system, this area was prosperous and commercial activities had reached its peak. 


\section{OVERVIEW OF THE STREET AND ALLEY SYSTEM OF THE QIANLONG DYNASTY}

By combing the development history of the Qianmen area, it can be known that the Qianlong reign of the Qing Dynasty was a typical heyday for the development of this area (Fang Biao, 2017; Yang Jianye. 2011). It is of considerable value to study the street and alley system and commercial activities as a case. Therefore, this study selects the Qianlong Dynasty as an example. Based on complete map of the capital in the fifteenth year of the Qianlong reign (1750), the picture in the book "Chen Yuan Shi Lue" by Wu Changyuan and map of Beijing City in Qing Dynasty in "Beijing Historical Atlas" by Mr. Hou Renzhi, the three materials confirm each other to draw a street and alley system map together.(Figure 2) alley system of Qianmen area in Qianlong Dynasty. In this process, follow the "longest and least" principle to transform the axis diagram, visually reflecting the connection between streets and lanes. Then, import the axis model into the Depth map analysis software. The line segment model is used to analyze the spatial integration and choice of the streets and alleys in the area.

\subsection{Integration analysis}

In spatial syntax analysis, Integration and Total Depth are the reciprocal of each other. A higher value of Total Depth means that it takes more steps to get from another space to this space after exhausting all possibilities, in another word, less reachability. The reciprocal of this value is the degree of integration. A space with a higher degree of integration indicates

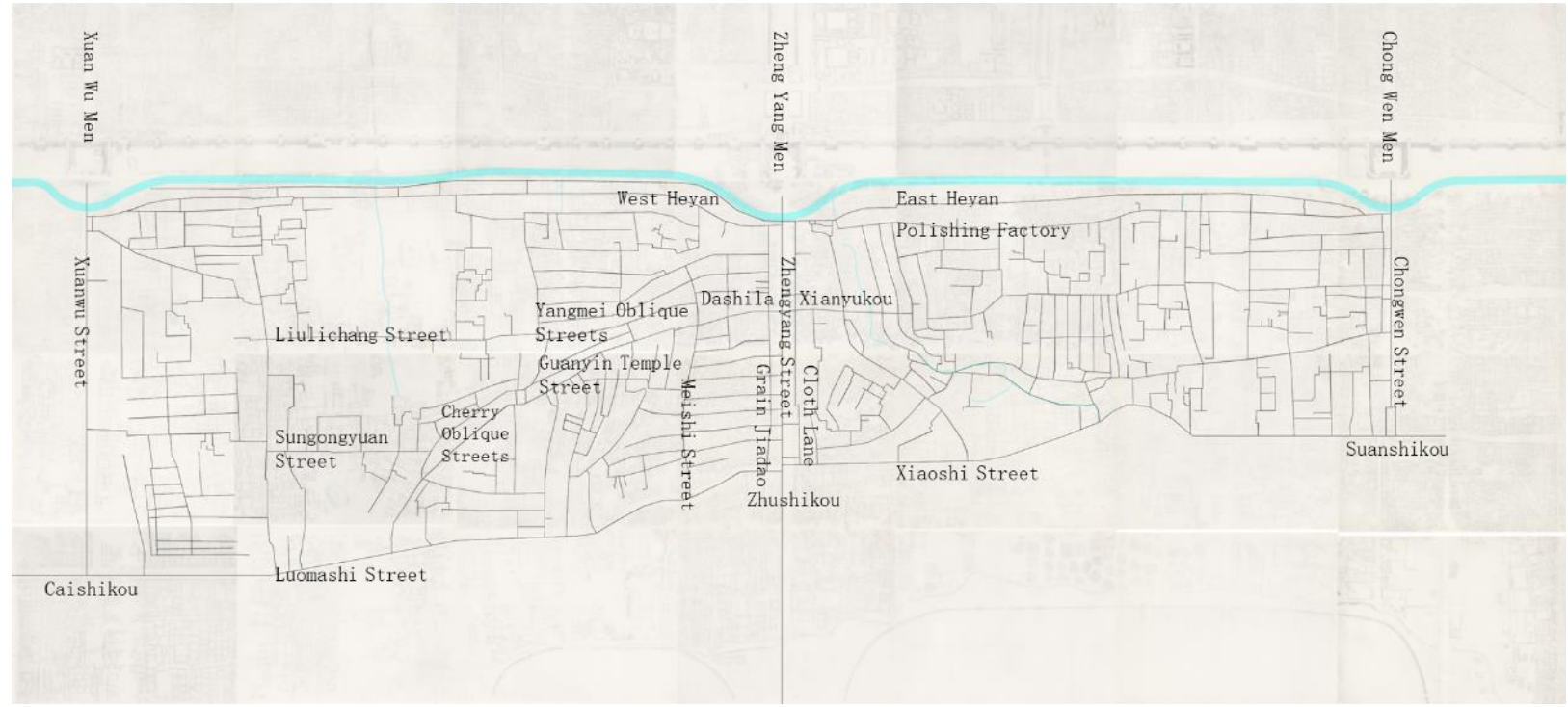

Figure 2. Street and alley map in Qianmen area during the Qianlong dynasty

Space Syntax could be very useful to help studying the street system in Qianmen area in this research (Zhou \& Zhang. 2018). Space syntax based on the topology to establish a cognitive model through computer and to quantify the space configuration, which was developed by Bill Hillier and his colleagues is different from the general traditional spatial analysis (Hillier \& Hanson, 1989). It is a theory and method to study the relationship between spatial organization and human society through the quantitative description of the spatial structure of human settlements, including buildings, settlements, cities and even landscapes.(Niu Qiang, 2012)

In this research, firstly, draw the axis diagram of the street and higher accessibility. Therefore, the degree of integration can be used to measure the potential of a space to attract arrival traffic. Integration is usually indicative to how many people are likely to be in a space, and is thought to correspond to rates of social encounter and retail activities (Hillier, 1996)The core of integration is the set of streets in a spatial structure where there are always a few overlapping axes with a high degree of integration, that is, the collection of those streets with the highest accessibility. Because of the high accessibility, many important urban functions are often gathered in these streets and alleys, which are economically, culturally and politically significant.

Since this research mainly focuses on the folk activities in the Qianmen area during the Qianlong reign of the Qing Dynasty, 


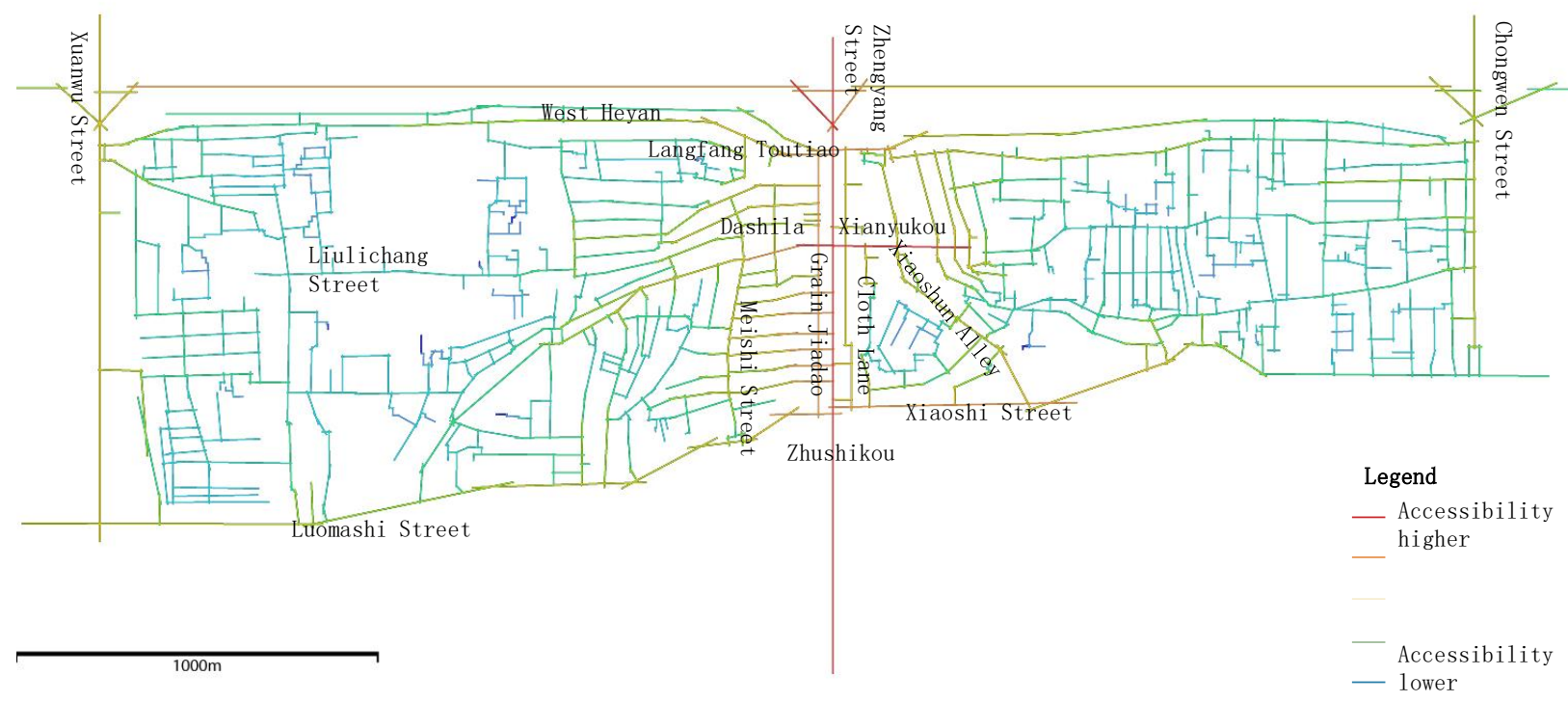

Figure 3. Integration of streets and alleys in Qianmen area during the Qianlong dynasty

the main modes of transportation are walking and carriage, the movement speed was relatively average and the variability was not significant. Therefore, the integration degree of the streets and alleys in Qianmen area and the core area of integration degree can be studied through the line segment model, and the traffic accessibility analysis can be obtained. (Figure 3) The warmer colored line in the figure indicates that the accessibility of the street is higher, and vice versa.

According to Figure 3, Zhengyang Street has the highest traffic accessibility in the entire area, followed by Xiangyukou and Dashila. At the same time, the accessibility of Grain Jiadao and Cloth Lane is also high. The accessibility of the streets and alleys in the Qianmen area gradually decreases from Zhengyang Street to the east and west sides. On the west side of Zhengyang Street, the accessibility of the entire area is relatively high from the West Heyan, Langfang Toutiao to Zhushikou, while it decreases significantly going west to the vicinity of Liulichang. On the east side of Zhengyang Street, the accessibility of Xianyukou Alley is significantly higher compared with other streets, while the accessibility of streets and lanes has declined sharply from Xiaoshun Alley and Changxiang Toutiao to the east. Comparing the east and west sides of Zhengyang Street, the accessibility of the Dashila area on the west side is significantly higher than that of the Xianyukou area on the east side, which may cause an imbalance in the socio-economic development of Qianmen area.

\subsection{Synergy analysis}

Synergy, or called intelligibility, reflects the individual's degree of understanding of the entire space when wandering and traveling in the space system, that is, the degree of difficulty for the individual to distinguish between the whole and the local when perceiving the space. A scatter plots was generated in the spatial syntax model.(Figure 4) $\mathrm{X}$-axis is defined as Integration[HH], Y-axis is defined as Integration R3. The former means global integration degree, the latter means local integration degree. The two data were subjected to correlation analysis. When the slope fitting degree $\mathrm{R}^{2}<0.5$, the horizontal axis and the vertical axis are considered irrelevant, that means the system's intelligibility is weak. When $0.5<\mathrm{R}^{2}<0.7$, the horizontal axis is correlated with the vertical axis. When $\mathrm{R}^{2}>0.7$, there is a significant correlation between the horizontal axis and the vertical axis, and the global comprehensibility of the local space is high.

In the scatter plot analysis of streets and alleys in Qianmen area, the global integration is not high, but the local integration is very high, $\mathrm{R}^{2}=0.283$, indicating that the intelligibility of this area was weak during the Qianlong reign. That is, at this time, the development of the streets and alleys system in the Qianmen area is relatively inward, and the local development within the system is better, but it is not greatly affected by the outside world. 


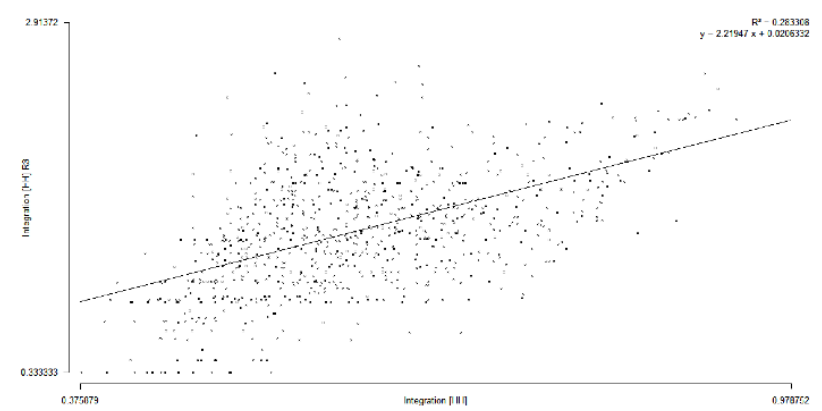

Figure 4. Scatter plots of streets and alleys in Qianmen area during the Qianlong dynasty the highest value in the entire area. Xiaoshi Street near Zhushikou, Xianyukou and Dashila are the second highest, followed by Grain Jiadao, Liulichang Street, Guanyin Temple Street, Annanying, Sungongyuan Street, West Heyan, East Heyan and Polishing Factory. Apart from those, the choice of other streets in the area is relatively low.

It shows that during the Qianlong reign of the Qing Dynasty, when walking was the predominant mode, Zhengyang Street was the most important traffic gathering street in the Qianmen area.

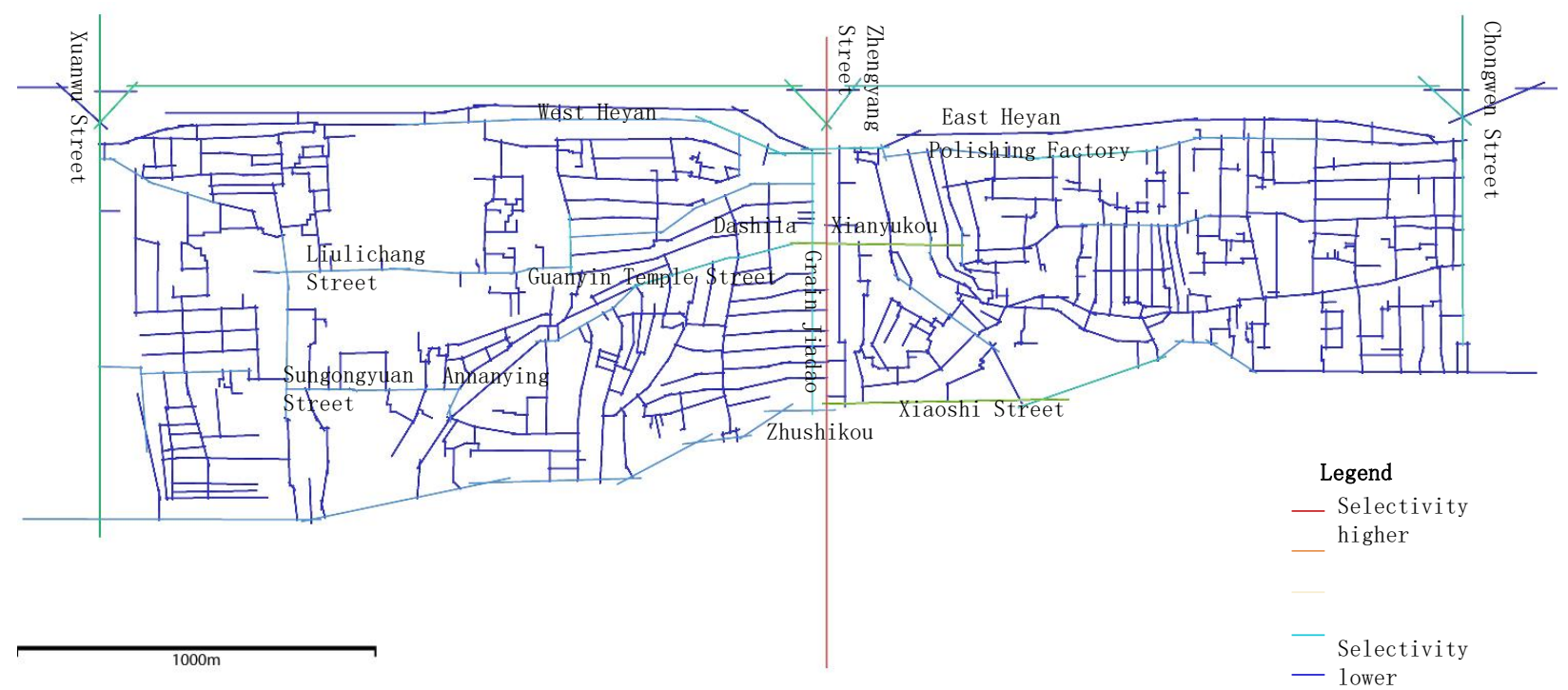

Figure 5. Selectivity map of streets and alleys in Qianmen area during the Qianlong dynasty

\subsection{Choice analysis}

Choice, or called selectivity, refers to the number of times a space appears on the shortest topological path, which can measure the potential of an element to attract crossing traffic. High choice indicates a space located on a shorter path from all origins to all destinations. In other words, a space with high choice means it is utilized by many pedestrians wishing to follow the shortest path to their destination (Kostakos, 2010). Choice is different from Total Depth, which is a measure of the potential of an element to attract arrival traffic. A comprehensive consideration of the two can understand the potential of an element to attract "traffic".

The selectivity of the street and alley system in Qianmen area was calculated. (Figure 5) The warmer colored line in the figure indicates that the selectivity of the street is higher, and vice versa. Zhengyang Street has a selectivity value of 0.763901 , which is
The east-west oblique traffic in the area is concentrated in Dashila, Xianyukou, Liulichang Street, Guanyin Temple Street, Annanying, Sungongyuan Street, West Heyan, East Heyan, and Polishing Factory. North-south traffic is concentrated in Grain Jiadao.

\subsection{Name classification and correlation analysis}

By sorting out the names of the streets and alleys in the map of Qianlong's capital, the roads in the Qianmen area are divided into five types according to their names: (1) streets, (2)lanes, (3)alleys, (4roads named by place, and (5)other roads without names. (Figure 6)

The red solid line represents street, orange line represents lane, yellow line represents alley, light green line represents road named by place, and blue line represents road without names. 


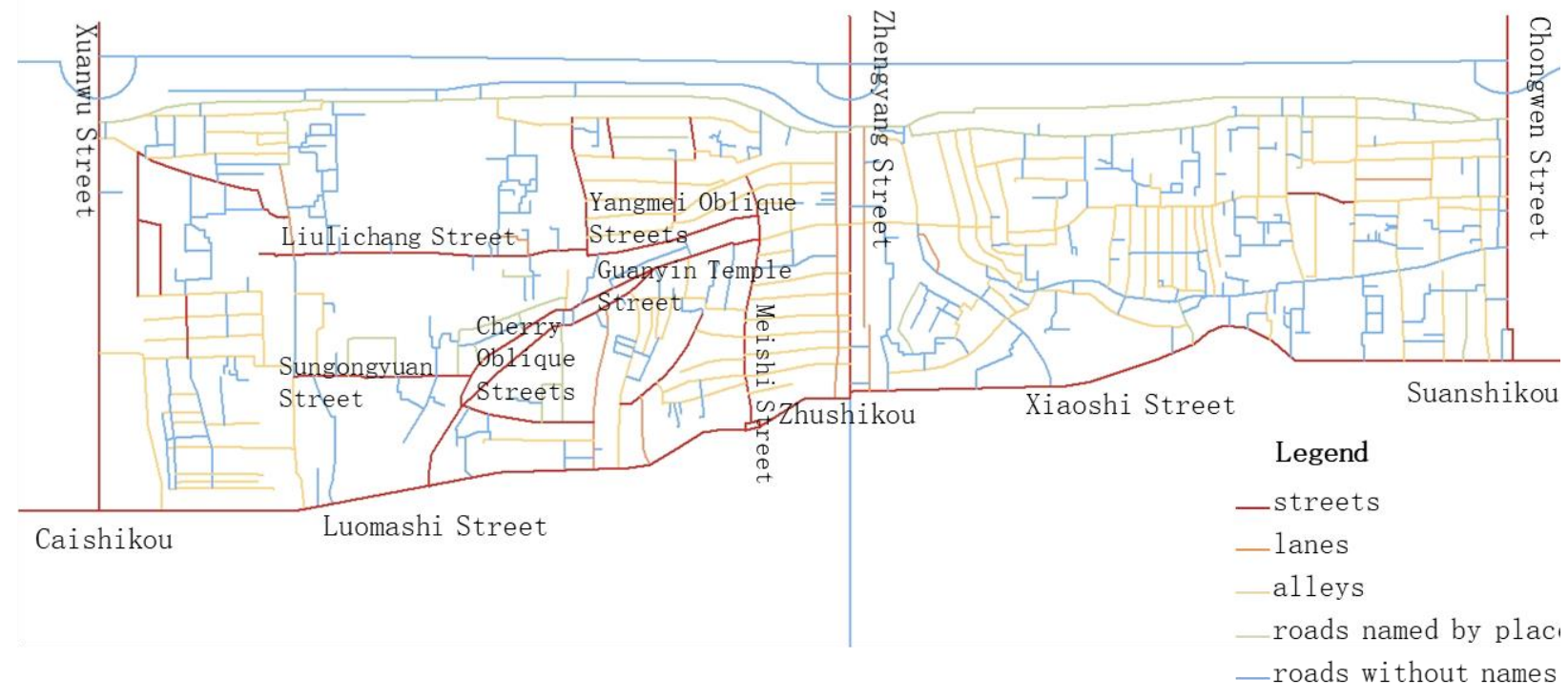

Figure 6. Name classification of streets and alleys in Qianmen area during the Qianlong dynasty

By comparing the road names in the Qianmen area and accessibility and selectivity analysis simulated by spatial syntax analysis, it can be seen that the importance of the streets in the west of Zheng Yang Men is higher than that of the east. The road named "street" mainly has a higher potential to attract crossing traffic, that is, the ancient people have a higher probability of choosing the road through Qianmen area. In addition to "street", it also includes "lane" and "alley" to name the road that attracts arriving traffic. Specifically, the road named after the sales industry has a higher potential to attract arrival traffic. For example, Meishi Street is a street where coal is sold. Xianyukou mainly sells live fish.

\section{OVERVIEW OF ARCHITECTURAL FORMS DURING THE QIANLONG DYNASTY}

In the study of the architectural forms along the streets in the full map of Qianlong's capital, it was found that there are four ways of building expression along the streets in the Qianmen area, namely:

1) Continuous building without doors.(Called "continuous building" for short in the following research) The drawing method of this kind of building does not depict the location of the building's opening door, but is represented by a continuous shophouse facade.

2) Building with doorways. (Called "architecture doorway" for short in the following research) In this architectural painting method, the location of the doorway is deliberately marked on the continuous building interface along the street.
3) Courtyard wall with doors. (Called "wall doorway" for short in the following research) In this kind of architectural painting, the bottom interface of the building is not open along the street, the building can only be entered after entering the inner courtyard through the door on the courtyard wall.

4) Continuous courtyard walls/Back of buildings without doors. (Called "continuous wall" for short in the following research) In this expression, the interface is a continuous solid wall or the back interface of the building, which should be an inaccessible space. (Figure 7)

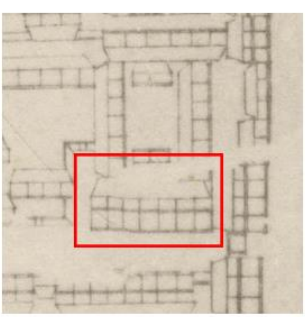

Continuous

building

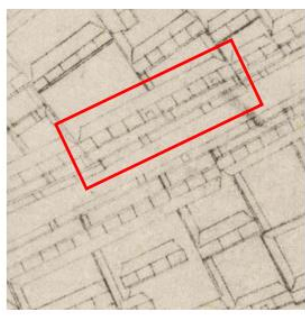

Wa11 doorway

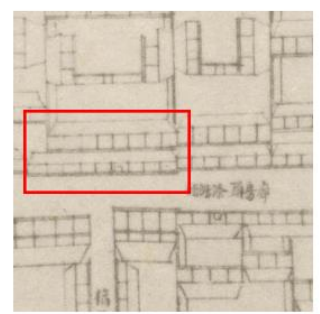

Architecture

doorway

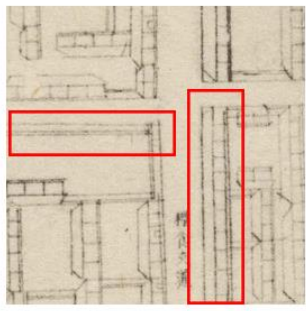

Continuous wa11
Figure 7. Four ways of building expression along the streets in the Qianmen area 


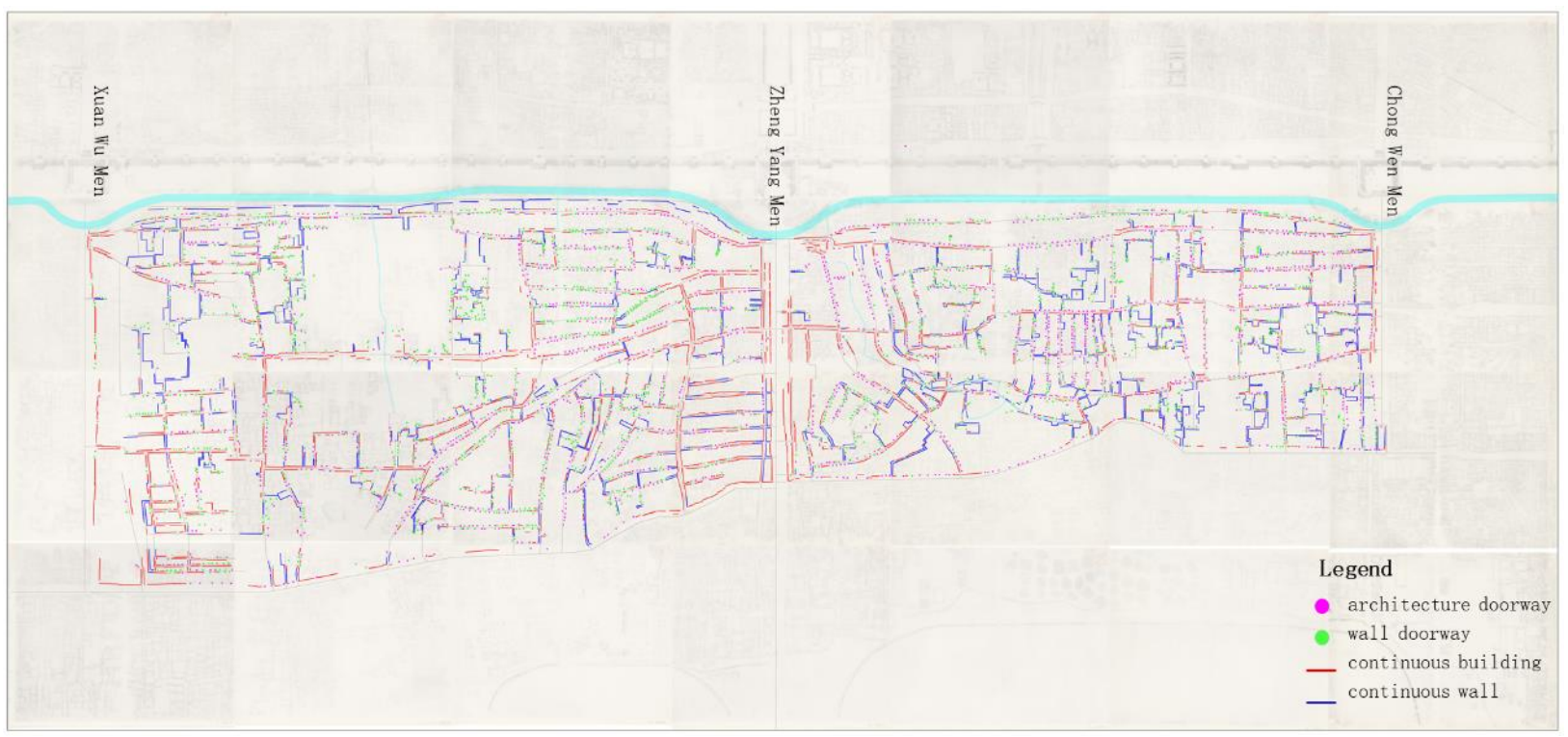

Figure 8. Abstract summary map of the four types of buildings drawing along the streets in the Qianmen area

Why do some buildings deliberately draw the doorway entrances along the street, but some did not while they are all the same courtyard-style buildings (Wang \& Jiang. 2009) in the entire map of Qianlong's capital? Do the different expressions of buildings along the street imply different public attributes? Perhaps the drafter considered that there is no need to draw the doorway because the bottom floors of the commercial shops along the street are all open, but the doorway is deliberately drawn for residential buildings or other buildings that are more of a residential nature, which need doorways to enter the courtyard? In order to clarify what kind of architectural public attributes correspond to the four different painting methods, and the relationship between the different functional buildings and the street and alley system in the Qianmen area. The method of typological classification was used in the study to abstractly extract the four types of architectural painting along the street.

The continuous building along the street is abstracted as a red solid line, the continuous wall as blue solid line, the doorway in the building as a purple dot, and the doorway on the wall as a green dot. Thus, an abstract summary map of the four types of buildings drawing along the streets in the Qianmen area is obtained (Figure 8).

\subsection{Distribution characteristics analysis}

The kernel density analysis method was used in the analyzing of distribution characteristics of the buildings. Kernel Density is used to calculate the unit density of the measured values of point and line elements in the specified neighborhood. In simple terms, it visualizes the distribution of discrete measurements over a continuous area. The result is a smooth surface with large intermediate values and small peripheral values. The raster value, which is the unit density, decreases to 0 at the neighborhood boundary. The calculation formula is:

$$
D=\frac{3\left(1-\text { scale }^{2}\right)^{2}}{\pi r^{2}}
$$

Among them, $r$ is the search radius, and scale is the ratio of the distance from the center of the grid to the point and line object to the search radius.

The distribution of different types of buildings in the Qianmen area can be analyzed with the help of kernel density analysis. Import the abstract points and lines diagrams of the above four types of buildings along the streets into the GIS software to analyze the kernel density. The nuclear density distribution of the four types of buildings is obtained. The darker colored in the graph indicates the higher density of that type of building.

\section{a. Distribution characteristics of continuous building}

On both sides of Zhengyang Street (that is today's Qianmen Street), there are densely distributed continuous building interfaces. This kind of building form is distributed more and densely on both sides of the Grain Jiadao, Meishi Street, Xianyukou, Cloth Lane, and Dashila Area. And it is more 


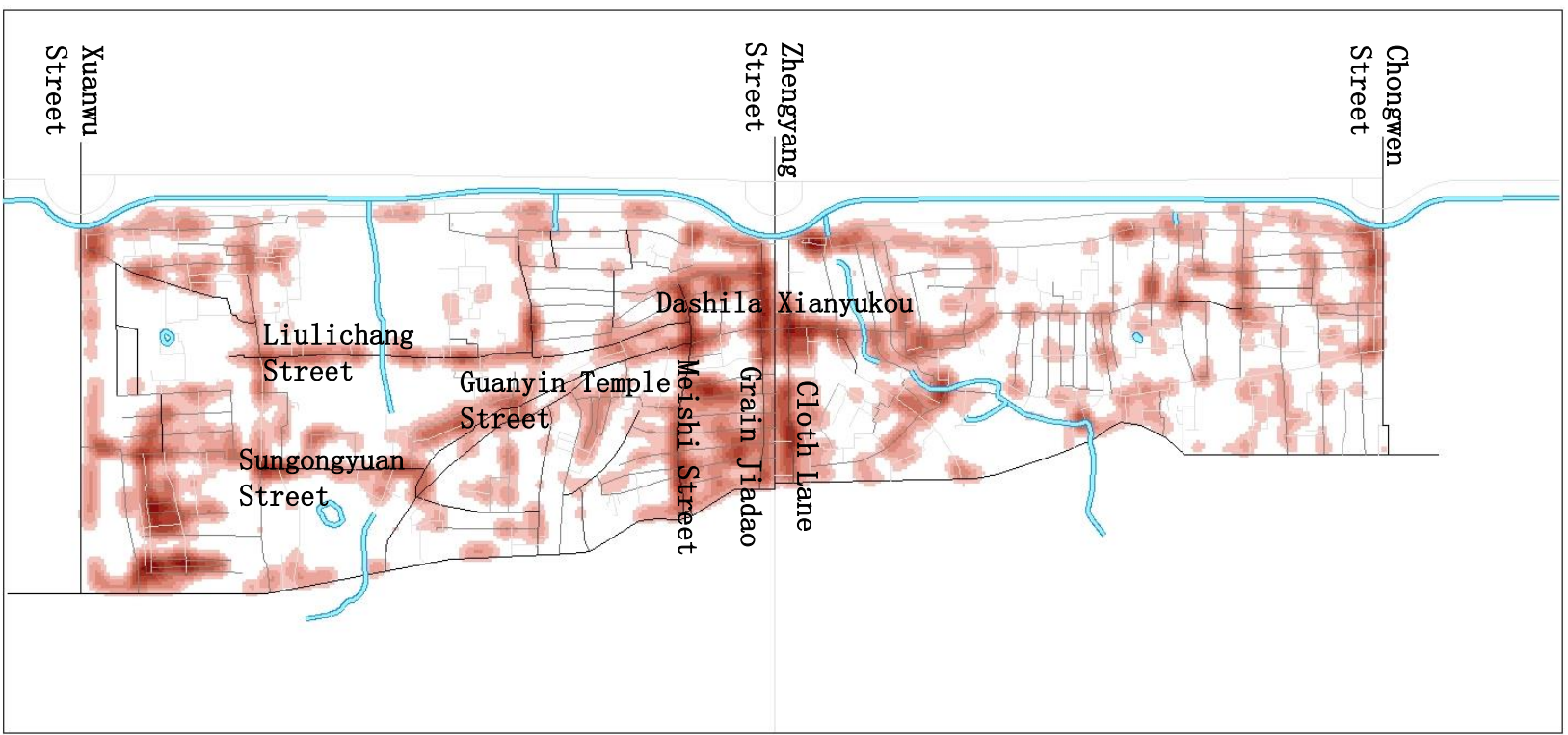

Figure 9. Distribution characteristics of continuous building

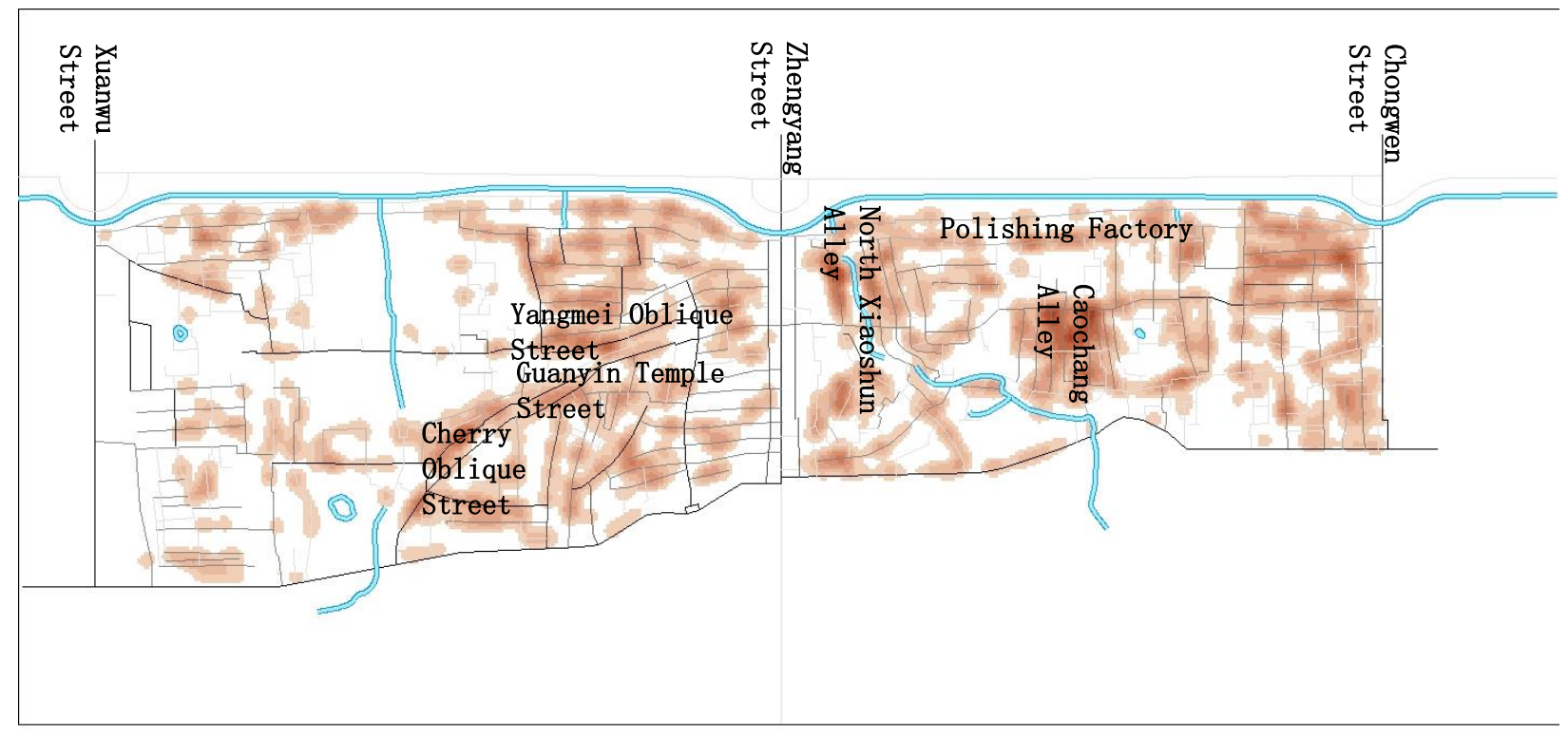

Figure 10. Distribution characteristics of architecture doorway distributed in Liulichang Street, the middle section of Sungongyuan Street and the northern section of Guanyin Temple Street. (Figure 9)

\section{b. Distribution characteristics of architecture doorway}

The form of architecture doorway is densely distributed along the Caochang Toutiao Alley to Caochang Shitiao Alley and from North Xiaoshun Alley to Polishing Factory on the east side of Xianyukou, and widely distributed in the area west of Meishi Street, especially gathering at Yangmei Oblique Street, Guanyin Temple Street and Cherry Oblique Street. (Figure 10)

\section{c. Distribution characteristics of wall doorway}

The architectural forms with doorways in the continuous wall are mainly distributed in Qudeng Alley, Guanyin Temple Street and Cherry Oblique Street on the west side of Zhengyang Street. There is less distribution in the area of Dashila and Xianyukou, almost none. (Figure 11) 


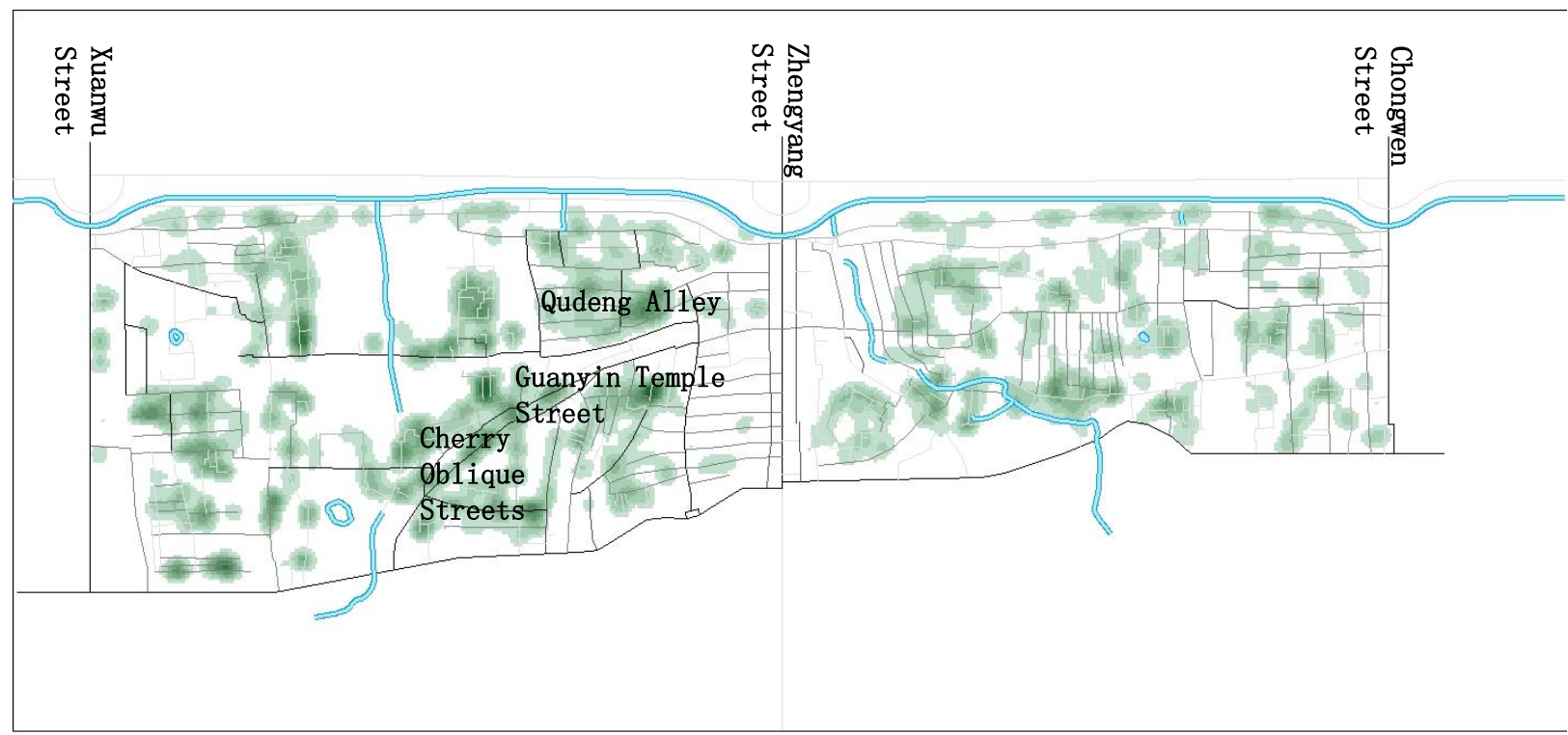

Figure 11. Distribution characteristics of wall doorway

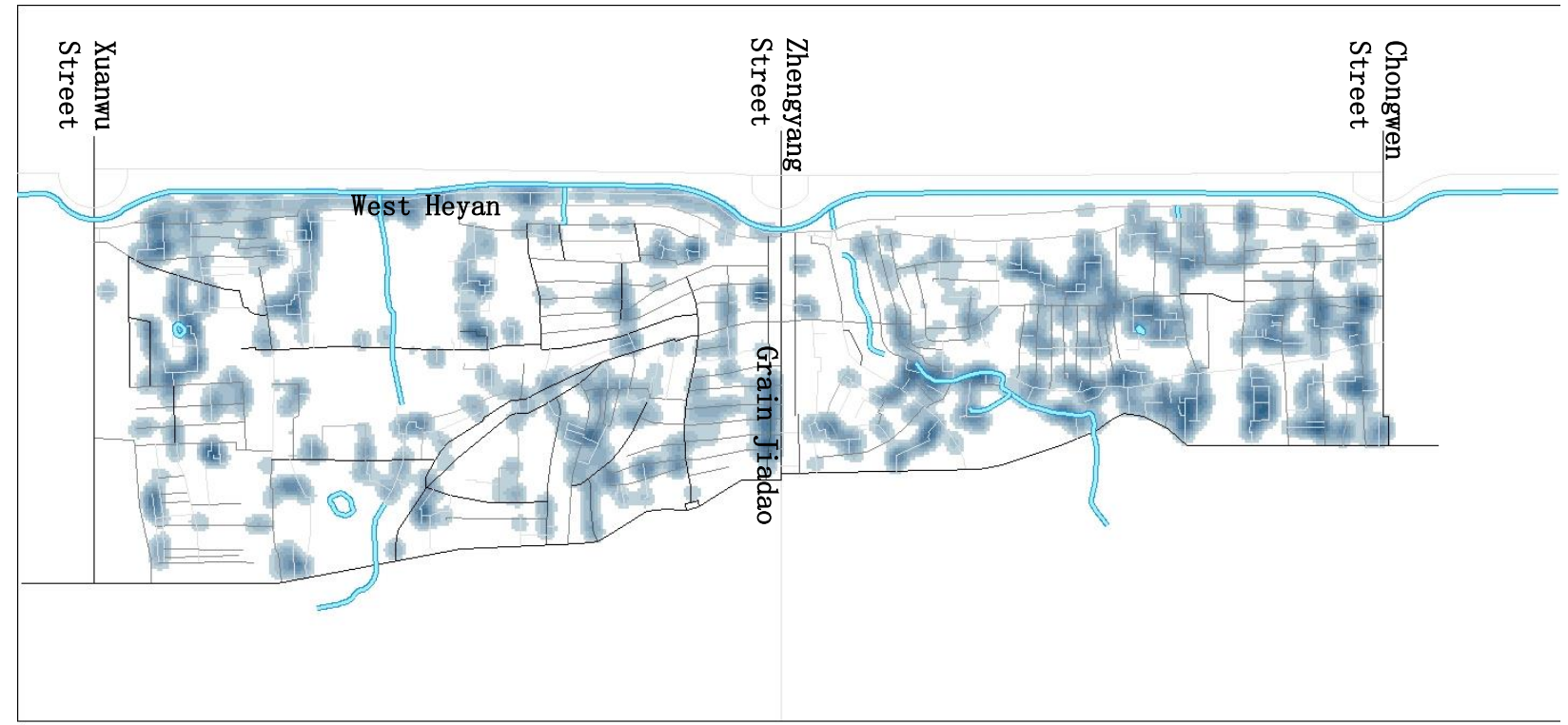

Figure 12. Distribution characteristics of continuous wall

\section{d. Distribution characteristics of continuous wall}

The form of continuous wall is relatively evenly distributed throughout the Qianmen area. There are two special cases. One is the southern section of Meishi Street, which is south of the intersection with Dashila. One is on both sides of the West Heyan. These two places show an obvious linear aggregation. The other areas are scattered in distribution. (Figure 12)

\subsection{Linear density analysis}

In order to perform the coupling analysis between the building type and the road type, the results of the building kernel density analysis need to be placed on the street closest to the building. The research method is to calculate the number of different building types onto the street closest to it. This statistical quantity is then divided by the length of the street to obtain the density of the distribution of a certain building form per unit road length. The density of the distribution of the four building types on the road is shown in the figure below. (Figure 13)

\subsection{Coupling analysis}

Through the coupling analysis of the distribution of the above four building forms along the five types of roads, it shows that: The forms of Architecture doorway mostly appear beside the roads of "Alley" and "roads named by place ".The form of Wall doorway mostly appears beside the roads of "Alley", "roads named by place " and " roads without names". Continuous 

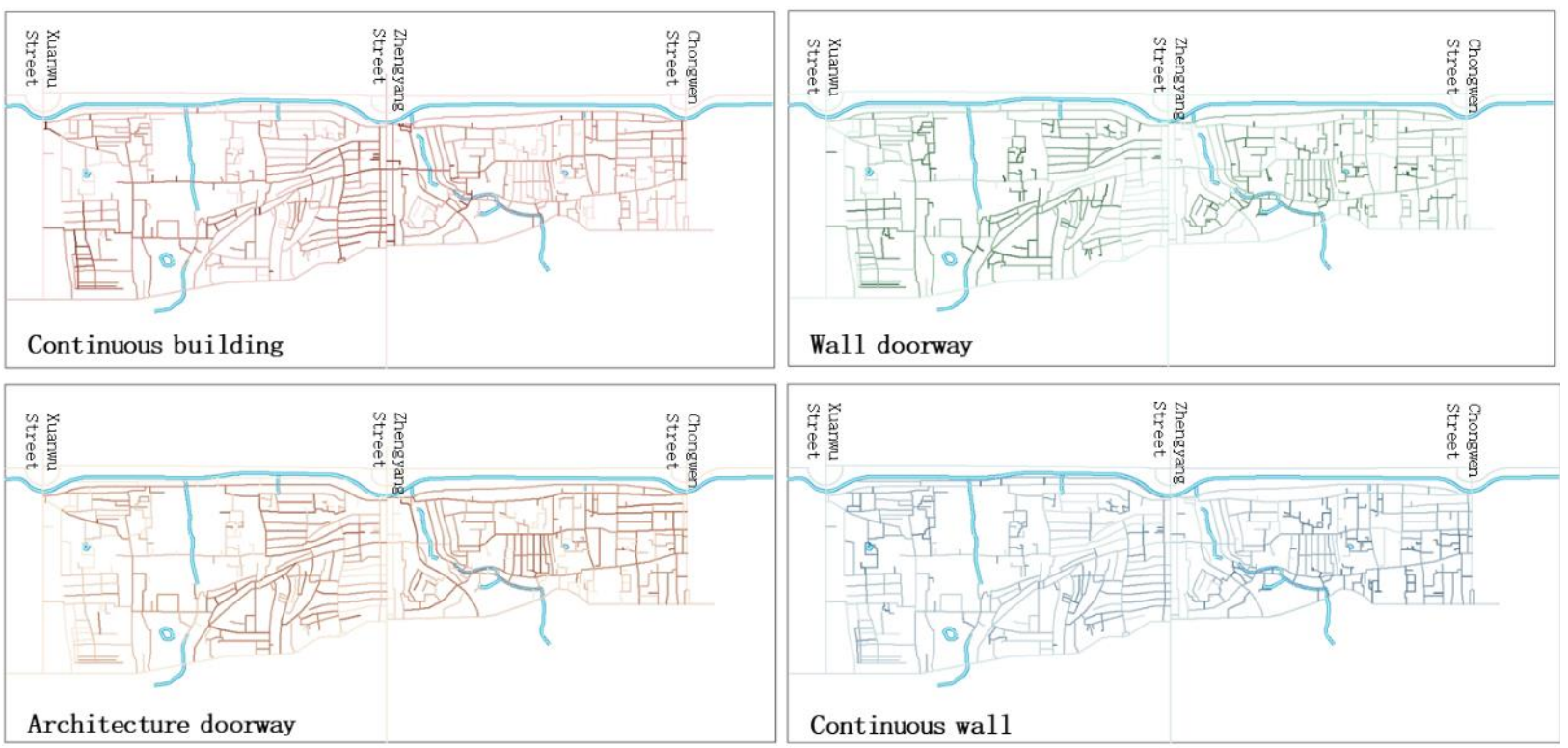

Figure 13. Analysis of four types of building form per unit road length

building forms mostly appear on the side of "streets" and "lanes". And the form of continuous walls mostly appears beside " roads without names ".(Figure 14)

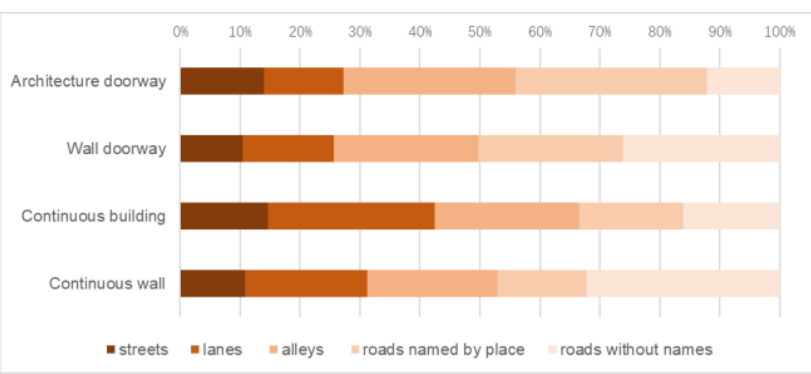

Figure 14. Coupling analysis of the distribution of building forms along the five types of roads

Combining the traffic accessibility analysis of different road classes and the publicness of the four building forms, the relationship between different building forms and the road system is as follows:

The continuous building forms with higher publicness are mostly located near "streets" and "lanes", which means that they have higher demand for both crossing traffic potential and arrival traffic.

The doorway of the building is close to the "alleys" and "roads named by place", indicating that it has higher requirements for the reachable traffic potential.

The accessibility of the road types near the wall doorway is moderate to low, while continuous walls mostly appear beside roads with low traffic accessibility.

\section{ALLEY SYSTEM AND COMMERCIAL ACTIVITIES}

According to historical research, during the Qianlong period of the Qing Dynasty, a commercial center of a certain scale was formed outside the three gates of Zheng Yang Men, Xuan Wu Men and Chong Wen Men (Xu Yitao. 1999). As Mr. Chen Zongfan said, the most commercial and dense streets in the outer city were Chongwen Street, Xuanwu Street and the area enclosed by the line of Caishikou - Luomashi Street - Zhushikou - Sanlihe Street - Suanshikou (Chen Zongfan,1991). As seen in the Qianlong Complete Map of the Capital, at this time, Zhushikou was divided into three sections, called West Zhushikou Street, West Liushujing, and Hufang Bridge, in order, due to the increase in the density of commercial buildings.

During the Kangxi and Qianlong reigns of the Qing Dynasty, the width of Zhengyang Street were reduced due to the commercial shacks occupying the street. " It has been a long time building shelters in front of Zhengyangmen as a place to live. In the 7th year of Chongzhen (1633), the lamp of Chengguo Zhu Chunchen's house was burned at night, so the Division of the destruction of the people's residence encroachment on the official street to build a shack to embrace the Quzhou Road."( Yu Minzhong, Qing Dynasty) By the Qianlong reign of the Qing Dynasty, the room of the mat shed was gradually changed to a 


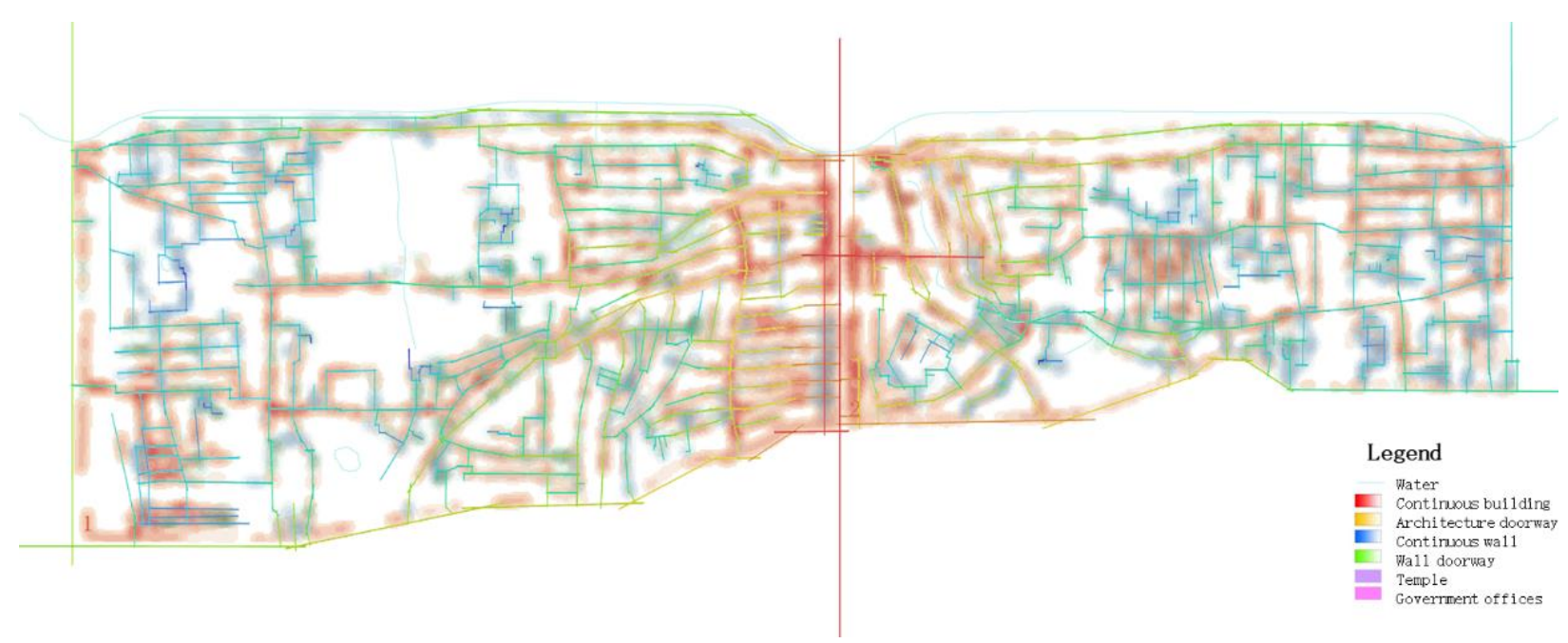

Figure 15. Building form kernel density superimposed street and lane integration map

formal house of brick and wood. The inner streets are formed behind the houses on the east and west sides of the Qianmen street, such as meat market, cloth market, jewellery market, and food store. In this way, the main street, Qianmen Street, becomes three streets (Duan Bingren, 2006).

In the research of the above-mentioned building forms, the continuous building form has the highest publicity, and the demand for both the potential of crossing traffic and arrival traffic is high. The way of expression is closest to the store form of retail business along the street in commercial activities. Complementing it is the form of architecture doorways along the street. Due to its higher demand for reachability traffic potential, it is closer to the commercial activity of reachable consumption, similar to hotels, theaters, restaurants, and clubs. The public nature of the wall doorway and the continuous wall forms, in contrast to the above two, is more focused on the privacy of the interface along the street. Therefore, it is considered to be close to the nature of residential buildings, or it needs to be considered in conjunction with commercial buildings as a commercial back street or freight transport channels.

The building kernel density analysis map obtained above was superimposed on the street integration degree map to observe the relationship between the number density of different forms of buildings and the distribution of street traffic potential, and then analyze the commercial activities in the street system. (Figure 15) In the data acquisition, because the ink lines on both sides of Zhengyang Street were broken and unrecognizable in the entire map of Qianlong's capital city (Zhu Shuyuan. 2007; Sun Guoqing. 2011), the types of buildings on both sides are not plotted. The judgment of commercial activities on this street is based on the draft of "Spring Poems in the Capital" scroll painted by Xu Yang (Qing Dynasty). (Figure 16)

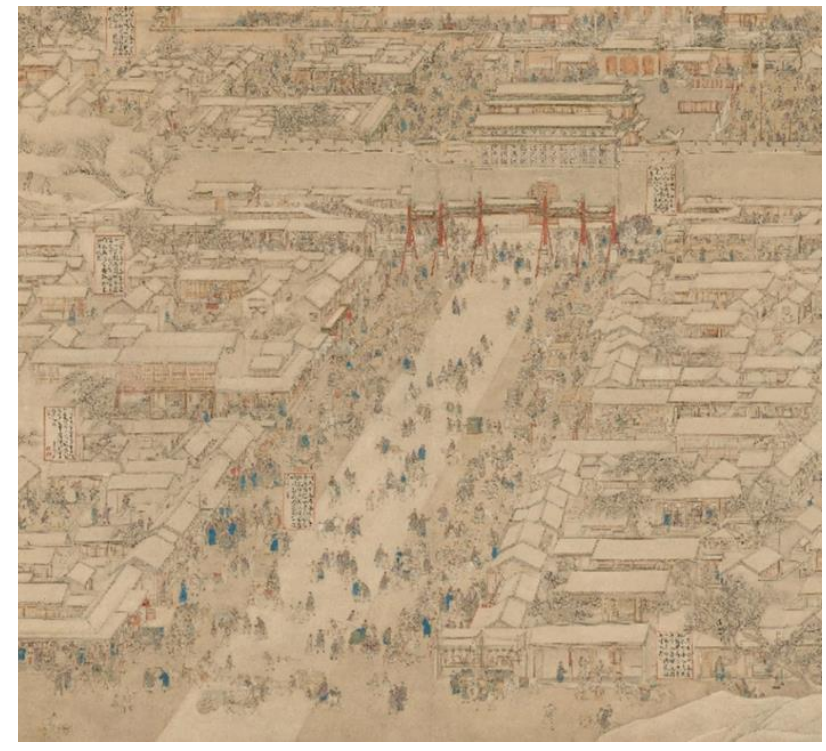

Figure 16. Zhengyang Street in "Spring Poems in the Capital" scroll painted by Xu Yang (Qing Dynasty)

Analyzing the figure 15 can get the characteristics of commercial activities in Qianmen area, the analysis is as follows (Figure 17):

In the Qianmen-Dashila area, Zhengyang Street is the main commercial street, with store fronts all facing Zhengyang Street. The northern section of the Grain Road is the main commercial street, while southern section of the Grain Lane is a commercial back street, which can be used as a backward freight channel for shops on Zhengyang Street. Langfang Toutiao Alley and Langfang Ertiao Alley are commercial-oriented main streets, while Langfang Santiao Alley and Doorframe Alley are 


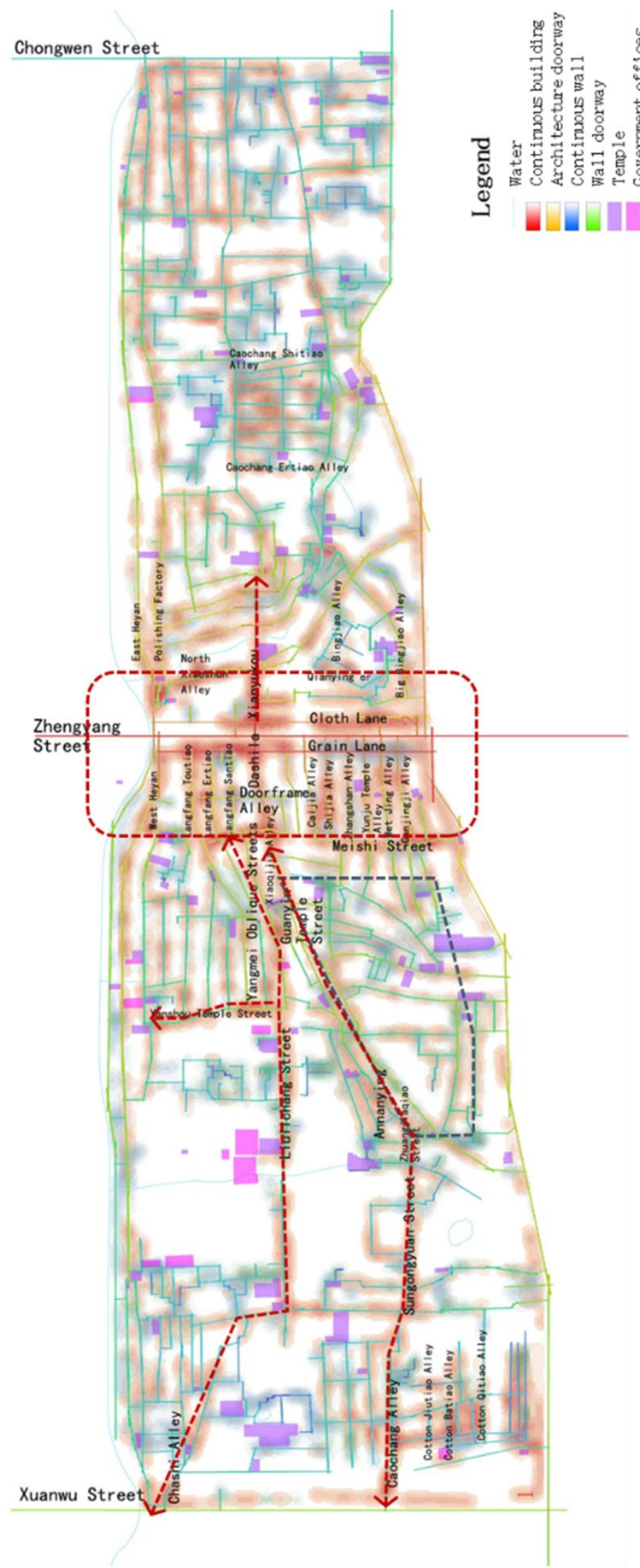

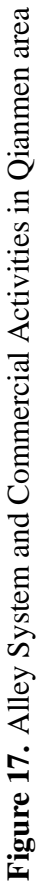


backward cargo streets. Dashila is an important commercial street, and Xiaoqijia Alley is a back street. Shijia Alley and Yunju Temple Alley are the main commercial street, and Zhangshan Alley is the back street. Wet Jing Alley and Ganjingji Alley have more commercial activities at the east and west ends, and the commercial atmosphere in the middle section is weak. Both the North and South Meishi Streets are important commercial main streets, with a large number of shops facing them.

From the west of the Dashila area to the Xuanwu Street area, there are two important east-west main commercial streets. First one is from Yangmei Oblique Streets to Liulichang Street to Chashi Alley. Second one is from Guanyin Temple Street to Annanying to Sungongyuan Street to Caochang Alley. And there are a considerable number of temples and government offices on these two main streets. Yanshou Temple Street is a section of the north-south main commercial street, and the area from Cotton Toutiao Alley to Cotton Jiutiao Alley is a small area of commercial blocks.

In comparison, the commercial development of the Xianyukou area is far inferior to that of the Dashila area on the west side of Zhengyang Street. The main commercial streets are Xianyukou Alley and Cloth Lane, North Xiaoshun Alley is a commercial back street, and Bingjiao Alley and Qianying'er are commercial backyard areas. To the east of the area, Caochang Toutiao Alley to Caochang Shitiao Alley is an internal residential area with scattered retail facilities. In addition, the commercial distribution of other areas in the Qianmen area is relatively scattered, and other obvious regularities have not yet been shown.

\section{CONCLUSION AND DISCUSSION}

The study shows that the following relationships existed between the street system and commercial activities in the Qianmen area during the Qianlong Dynasty.

The commercial activities in the Qianmen-Dashila area present a network-like structure, with corresponding service backstreets existing behind the adjacent neighborhoods of the commercial front streets. Zhengyang Street and Meishi Street, as important external commercial boundaries of the area, have high vitality, and it can be inferred that the commercial types are mainly sales industries, which need to occupy important interfaces along the streets. The commercial activities in the area west of Meishi Street are mainly based on a linear layout, with two important commercial main streets being " Yangmei Oblique Streets Liulichang Street - Chashi Alley" and "Guanyin Temple Street Annanying - Sungongyuan Street - Caochang Alley" respectively, with more temples and official offices connected. Among them, the building form of the Bada Alley area is mainly from the wall into the courtyard type, which has a certain correspondence with its commercial type. In contrast, the Xiangyukou area east of Zhengyang Street is less dynamic and has not formed a relatively complete commercial system. It only focuses on the linear commercial activities of Xiangyukou and Cloth Lane. The corresponding relationship between the front commercial street and the back court is relatively low.

In general, the layout of commercial activities in the Qianmen area during the Qianlong Dynasty is relatively consistent with the accessibility of streets and alleys. Most of the commercial stores are located on both sides of the streets and alleys with higher integration and selection, reflecting the main commercial streets where the vitality of the area was concentrated.

Based on the high demand for traffic accessibility of commercial activities, this study judged the possible corresponding architectural public attributes of the four types of buildings along the streets in Qianmen area during Qianlong Dynasty through typological classification, and then analyzed the commercial activities in this area. However, since the historical excavation of the entire map of Qianlong's capital has not yet shown a clear textual research on the corresponding architectural drawing methods and functional properties, there is still room for further demonstration of the reliability of the inferences of this study. In the follow-up study, if the boundary of the plot, the functional attributes and the specific door opening direction of each courtyard can be clarified, it can provide a clearer evidence base for the flow of people and goods in and out of the commercial activities, and the relationship between the temples and government offices and the commercial layout can also be further explored, thus further enriching and improving the research on commercial activities in the Qianmen area during the Qianlong period. 


\section{REFERENCES}

Xiong Mengxiang, Yuan Dynasty: Analysis of the Lost Collection of Xi Jin Zhi, 1983 Beijing Ancient Books Publishing House.

Ming Hui Yao, Ming Dynasty: 80 volumes, volume 50, civil administration 1,Engraved copy of Yonghuaitang in the thirteenth year of Guangxu, Qing Dynasty.

Wu Changyuan, Qing Dynasty: Chen Yuan Shi Lue, 16 Volumes: Volume 10, Qianlong Chibei Cottage, Qianlong, Qing Dynasty.

Yu Minzhong, Qing Dynasty: Ri Xia Jiu Wen Kao, Volume 160: Volume 6, The Complete Book of Four Banks of Wenyuan Pavilion, Qing Dynasty.

Shun Tian Fu Zhi, Qing Dynasty: Volume 130: Volume 14, Reprint of 15 years carved in the 12th year of Guangxu, Qing Dynasty.

Da Qing Hui Dian Ze Li, Qing Dynasty: Volume 180: Volume 150, The Complete Book of Four Banks of Wenyuan Pavilion, Qing Dynasty.

Chen Zongfan, 1991, Yan Du Cong Kao, Beijing: Beijing Ancient Books Publishing House, (10)

Hillier, B., \& Hanson, J. ,1989: The social logic of space. London: Cambridge university press.

Hillier, B. ,1996: Cities as movement economies. Urban Design International, 1(1),41-60.

Kostakos, V. ,2010: Space Syntax and Pervasive Systems, 99, 31-52.

Hou Renzhi, 1988: Beijing Historical Atlas, Beijing: Beijing Publishing House, 31-32.

Niu Qiang. 2012: Urban Planning GIS Technology Application Guide. Beijing: China Construction Industry Press, (02): 223.
Fang Biao, 2017: Beijing Xicheng District Cultural Relics Conservation Research Institute. A Brief History of Beijing. Beijing: Beijing Times Chinese Books Bureau, (09):187.

Xu Yitao. 1999: Research on the traditional commercial blocks and commercial buildings outside the three gates of Beijing. Nanjing: Southeast University.

Duan Bingren, Luo Baoping, Zhang Huiqi. 2006: Qianmen· Dashila. Beijing: Beijing Press, (04).

Chen Wei. 2007: The southern end of the celestial dynastyBeijing outer city commercial activities and urban pattern around the 32nd year of Jiajing (1553).Architect, (03):57-68.

Yang Jianye. 2011: The Legend of Qianmen and Qianmen. Beijing: China Society Press, 15.

"Beijing History" Writing Group, Department of History, Peking University. 1985: History of Beijing. Beijing: Beijing Publishing House.

Zhou Jiaying, Zhang Jingqiu. 2018: Study on the Spatial Form of Historic Districts Based on Space Syntax-Taking the Qianmen Area of Beijing as an Example. Journal of Beijing Union University, 32(01):22-27.

Zhu Shuyuan. 2007: An overview of Qianlong's "The Complete Map of the Capital"[C]. China Forbidden City Society. Proceedings of China Forbidden City Society (Volume Six Part 1). Forbidden City Society of China: China Forbidden City Society, 329-337.

Sun Guoqing. 2011: The complete map of Qianlong's capital. Map, (03):132-133.

Wang Lumin, Jiang Zhidan. 2009: The adoption of courtyard houses in ancient Beijing and the position of architectural history research. Architect, (4): 71-76. 